\title{
Spatial and Temporal Changes of Forest Cover in Minneriya National Park Using GIS and Remote Sensing
}

\author{
Dilanjani H.U.K. *and Ranagalage M.M. \\ Department of Environmental Management, Rajarata University of Sri Lanka \\ *dilanjanisameera@gmail.com
}

\begin{abstract}
Forest cover change can be identified as both combining with natural influence and also the anthropocentric activities. Minneriya National Park is a unique area of interest to visitors and researchers. However, at present climatic change and human interference such as some of the development projects that have a negative impact to the park. Therefore identification of the changes of forest cover in Minneriya National Park is timely valuable. GIS is more effective tool for identify the change detection of forest cover. The general objective of this study is to identify the spatial and temporal changes of forest cover in Minneriya National Park using GIS and Remote Sensing.

This research mainly depended on secondary data of land use maps. GIS analysis was conducted for the identification changes took place over time on the park area using Google images. Park area changes data were collected from 2000 to 2014, within 14 year period as using secondary data for the analysis using only GIS. By using 2000 land sat data and 2014 Google map it created a new map by georeferncing. By the supervised classification and digitization it could be created the land use map of 2000 and 2014. By overlaying of these two maps the changes of forest cover were identified within the 14 year period.

The change of forest area has been identified. In 2000, forest cover was $42.67 \mathrm{~km}^{2}$ and there was a reduction in 2014 to be $36.65 \mathrm{~km}^{2}$. The scrub area changes from $21.2 \mathrm{~km}^{2}$ in 2000 to $27.83 \mathrm{~km}^{2}$ in 2014 Therefore scrub areas were increased during the last 14 year period . In 2000 tank area was $22.89 \mathrm{~km}^{2}$ which was reduced in 2014 to $22.37 \mathrm{~km}^{2}$. Therefore the comparison of land use maps of 2000 and 2014 showed the considerable changes in forest areas, scrub areas and the tank areas.
\end{abstract}

Keywords: Forest cover, Minneriya National Park, Geographic Information System, Remote sensing 